\title{
Emotion regulation and healthy behaviors of the body energy balance in adults: $A$ review of evidence
}

\author{
Andrés Gómez-Acosta; Constanza Londoño Pérez
}

How to cite this article:

Gómez-Acosta, A., \& Londoño Pérez, C. (2020). Emotion regulation and healthy behaviors of the body energy balance in adults: A review of evidence. Acta Colombiana de Psicología, 23(1), 349-365. http://www.doi.org/10.14718/ACP.2020.23.2.14

Recibido, abril 26/2019; Concepto de evaluación, diciembre 13/2019; Aceptado abril 4/2020

\author{
Andrés Gómez-Acosta* \\ Universidad Católica de Colombia, Bogotá, Colombia \\ ORCID: https://orcid.org/0000-0002-7932-0466 \\ Constanza Londoño Pérez \\ Universidad Católica de Colombia, Bogotá, Colombia \\ ORCID: https://orcid.org/0000-0003-3273-3658
}

\begin{abstract}
There is no document that analyzes the state of the art of scientific research published between 2013 and 2018 in relation to possible interdependence links between emotional regulation [ER] and healthy behaviors associated with Body Energy Balance [BEB] (physical activity, balanced diet and sleep hygiene). To achieve this purpose, an exploratory systematic review was conducted, whose search criteria were "emotion regulation", "emotion dysregulation" connected with the Boolean operator "AND" to the keywords "sleep hygiene", "eating behavior" and "physical activity". Terms like "alexithymia", "depression", "stress", "negative emotions", and "rumination" were omitted. The methodological quality of the evidence was assessed with a patented rubric. After applying the analysis criteria, 35 articles were obtained, reporting the existence of reciprocal associations and interactions between ER and at least one of the three behaviors associated with BEB were analyzed. It is concluded that, despite the importance of these behaviors in the vital maintenance of people and the clear impact that emotional regulation has on them, their research has not been sufficient, and more empirical studies in this regard in Latin America are needed.
\end{abstract}

Keywords: Emotion Regulation (ER), Physical Activity (PA), Healthy Eating (HE), Sleep Hygiene (SH), Body Energy Balance (BEB).

\section{Regulación emocional y conductas de balance energético corporal en adultos: Una revisión de evidencia}

Resumen

\begin{abstract}
No existe en la actualidad un documento que analice el estado del conocimiento de las investigaciones científicas publicadas en los últimos años con respecto a los posibles vínculos de interdependencia entre la regulación emocional (RE) y las conductas asociadas al balance energético corporal (BEC) — actividad física, alimentación balanceada e higiene del sueño-. Por tanto, para lograr dicho propósito, en el presente estudio se realizó una revisión sistemática exploratoria, cuyos criterios de búsqueda fueron los términos "emotion regulation" y "emotion dysregulation", conectados con el operador booleano "AND" a las palabras clave "sleep hygiene", "eating behavior" y "physical activity" — términos como "alexithymia", "depression", "stress", "negative emotions", y "rumination" fueron omitidos—; donde se valoró la calidad metodológica de la evidencia de los artículos a partir una rúbrica patentada. Tras aplicar los criterios de inclusión establecidos, se obtuvo un total de 35 artículos que reportaban la existencia de asociaciones e interacciones recíprocas entre la RE y al menos una de las
\end{abstract}

Av. Caracas N. 46-40. Tel.: (+0571) 3277300, ext. 5071. clondono@ucatolica.edu.co 
tres conductas asociadas al BEC. Como resultado, se puede afirmar que, a pesar de la importancia de dichas conductas en el mantenimiento vital de las personas y el claro impacto que tiene la regulación emocional sobre ellas, su estudio no ha sido suficiente, y por tanto se necesitan más investigaciones empíricas en el contexto latinoamericano.

Palabras clave: regulación emocional, actividad física, alimentación saludable, higiene del sueño, balance energético corporal.

\section{Introduction}

Living beings need to balance the caloric expenditure through an efficient recovery of body energy. Therefore, if the systems responsible for this balance fail, the body is induced to a progressive deterioration of increasing acceleration, which can make them more vulnerable to getting sick (López-Espinoza et al., 2014; Romieu et al., 2017). The World Health Organization -WHO (2010) states that leading a sedentary lifestyle, having an inappropriate diet and, sacrificing hours of sleep or of quality sleep, can significantly affect the cost-recovery equation and contribute to the development of chronic not transmissible diseases (heart disease, cancer and diabetes, among others), which seriously affect the quality of life and can cause premature deaths (Lim et al., 2016).

Consequently, it is recommended the sustained realization of the behaviors associated with the Body Energy Balance (BEC), which are: a) Physical Activity (PA) understood as any movement produced by the contraction of musculoskeletal system that results in increase of caloric expenditure above baseline (Baker, Dobbins, Soares, Francis, Weightman, \& Costello, 2015); b) Healthy Eating (HE), defined as the set of actions related to the consumption of balanced foods in response to motivations and availability of biological, psychosocial and contextual type (López-Espinoza et al., 2014); and c) Sleep Hygiene (SH) conceived as the rest that allows the efficient restoration of body tissues for proper functioning (Irish, Kline, Gunn, Buysse \& Hall, 2014).

On the other hand, ER is defined as the way in which people manage the expression, suppression and intensity of emotions, based on both personal goals and the specific situations with which they interact at moment (Gross, 2014); the ER has been linked to the health-disease process in two ways: 1) by the influence of negative affective states (anger, anxiety and depression) on physiology, through psychoneuro-endocrine-immunological and epigenetic mechanisms, which contribute to the increase in allostatic load (Uskul \& Horn, 2015), as well as to the imbalance of BEB and the concomitant development of systemic diseases (DeSteno, Gross, \& Kubansky, 2013); and 2) through the optimal development of ER phases in the psychobiological and sociocultural domains that involve risk assessment, subjective experience of felt emotion, decision making (mediated by cognitive processes), and sustained performance of healthy behaviors (like those of the BEB) that allow to minimize the risk, reduce the associated allostatic load and maximize the benefits (Gross, 2015; Waters, McQueen \& Cameron, 2014).

People with RE problems report progressive deterioration of their quality of life and considerable decline in psychological well-being (Etchemendy et al., 2016), with occasional diagnoses of mental problems such as alexithymia, disruptive behavior, attention-hyperactivity deficit, generalized anxiety, depression, suicidal ideation, use of psychoactive substances and obsessive-compulsive personality disorders (González, Ramírez, Del Mar \& Londoño, 2017; Sheppes, Suri \& Groos, 2015). Similarly, some people believe that to counteract unpleasant moods they should include incentives and pleasant activities, but they encourage greater activation of hedonic schemes, procrastination and, ultimately, refer less effective skills for an adequate ER to possible temptations that compromise their health (Wagner \& Heatherton, 2014).

On the contrary, those who learn to regulate their emotions in order to attenuate, maintain, amplify or change their behavior in accordance with the specific ecological and social objectives and context (Hoorelbeke, Koster, Demeyer, Loeys, \& Vanderhasselt, 2016; Seligowski \& Orcutt, 2015) are better adjusted to challenging daily events, and show better indicators in both physical health (Appleton \& Kubzansky, 2014; Jenaabadi, Ali-Ahani, \& Sabaghi, 2015) and mental health (Bonanno \& Burton, 2014; Gross, 2015) than those who do not regulate their emotion (Etchemendy et al., 2016).

There are reviews aimed at identifying the available scientific evidence, carried out with the purpose of analyzing in depth the relationship between poor emotional regulation and the reporting of events in mental health in adults (Hu et al., 2015). However, although there are studies where ER is related to the development of healthy habits such as balanced diet, sleep hygiene and adequate physical activity of adults (Lee et al., 2016), there are no reviews regarding the way in which ER is linked to behaviors related to body energy regulation and that highlight the importance of this psychological process in the sustained execution of those behavioral aggregates that, in interaction, are responsible for the BEB.

For this reason, the aim of this systematic review was to determine the state of the scientific knowledge about the possible interdependence between emotional regulation 
(ER) and behaviors associated with Body Energy Balance BEB (physical activity, balanced diet and sleep hygiene) in the adult population.

\section{Method}

Design

This research corresponds to a descriptive type documentary analysis carried out under the exploratory systematic review methodology, taking into account the criteria set forth by Manchado et al. (2009).

\section{Documentary sample}

The final documentary sample consisted of 35 research report articles identified with the inclusion criteria described below (see figure 1).

\section{Inclusion criteria}

The defined search terms were, "Emotion Regulation" or "Emotion Dysregulation" connected with the Boolean operator "AND" to the keywords "Sleep Hygiene", "Sleep" "Eating Behavior" and "Physical Activity". The only research considered were: a) experimental studies evaluating psychological treatments aimed at optimizing ER to increase at least one of the behaviors associated with BEB; b) correlational studies aimed at identifying significant relationships between ER and at least one of the three behaviors associated with BEB; c) papers in which ER has been measured with an instrument validated specifically to account for this psychological variable and not for another such as self-control, affection, emotions, among other overlapping concepts.

\section{Exclusion criteria}

Conceptually overlapping terms were omitted in the search, but not homologous ones such as "alexitimia", "depression", "stress", "negative emotion", "emotional intelligence" and "rumination". Similarly, gray literature, theoretical articles, narrative reviews, letters to the editor and empirical works with other populations were not included.

\section{Data collection and evaluation of the studies' methodolo- gical quality}

The sample covered published or in press articles of scientific journals compiled by the databases Academic Search Complete, Virtual Health Library [VHL] of the Pan American Health Organization [PAHO], Embase, Medline, PlusONE, PsyArticles, PubMed, Redalyc and Science Direct, published from 2013 onwards.

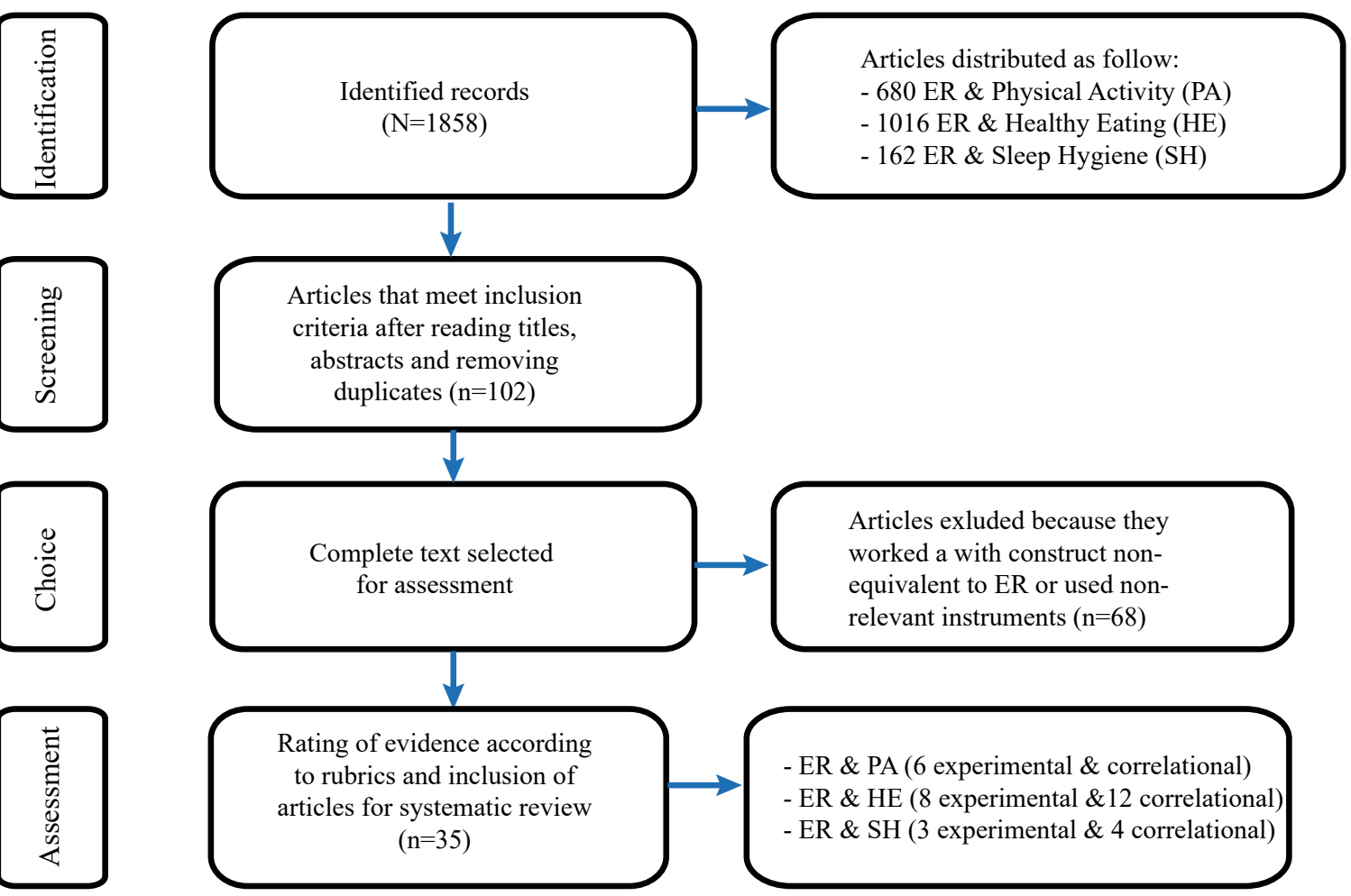

Figure 1. Flow chart of the articles' selection process. Source: prepared by the authors 
352

The final sample was rated according to the "Instrument to assess the methodological quality of the articles selected for meta-analysis ${ }^{\circledR}$ " designed, validated and patented by Gómez-Ortega \& Amaya-Rey $(2013,2016)$, which proposes criteria for judging the methodological quality of scientific articles. This rubric evaluates the design, the sampling rigor, the instruments, collection and analysis of information, the presentation of results, and the discussion argumentation.

\section{Ethical considerations}

This review was carried out within the framework of a doctoral thesis approved by the ethics committee of the Universidad Católica de Colombia (Act 4, issued in October 2018); also, the referenced texts were consulted through access to freely accessible repositories and the databases subscribed with this university exclusively.

\section{Results}

The analysis of the documents that relate the RE with BEB behaviors (physical activity, healthy eating and sleep hygiene) is presented below. The table 1 maintains the same provision, in addition to an alphabetical order authors of the studies.

\section{$R E$ and Physical Activity}

Regarding this item, eight articles were found, of which six were experimental and two was correlational. None of them indicates the effect size explicitly, although all detail the inclusion and exclusion criteria defined for the selection of the sample, describe the statistical procedures implemented for the analysis of the information, point to significant findings that answer the research question and verify the proposed hypothesis. Similarly, it is possible to identify in them consistency between the results, the conclusions and the limitations described.

However, two of them do not define conceptually and operationally the variables of interest; three of them (among which two experimental studies are included) do not mention a sufficient degree of control to allow establishing a high internal validity; three do not present the reliability/validity indicators of the measurement instruments implemented; one of the studies was not clear in describing the way in which the information was collected, and four do not report the procedure used to calculate the sample. As these studies were concentrated in only two English-speaking countries (the United States and the United Kingdom), one in Poland, and other in Taiwan.

Regarding the contribution of these documents to the scientific understanding, it was found that those who perform moderate aerobic exercise show more neuronal efficiency and cognitive control underlying ER (Hwang et al., 2018), as well as greater ability to reinterpret negative emotional stimuli (Ligeza et al., 2019), without significant differences between those who perform moderate cardiovascular exercise and those who participate in stretching activity (Berstein \& McNally, 2017).

Along the same lines, Wollenberg, Shriver and Gates (2015) found that high performance athletes have better positive reappraisal skills in relation to non-athletes, as well as greater satisfaction with their body image, self-esteem and lower risk of triggering any eating disorder. This same finding is confirmed by Wagstaff(2014), who shows that by subjecting three groups of athletes to situations that induce conditioned emotional suppression, the perception of physical exertion increases. On his part, Lane et al. (2015) found that, although ER intervention does not necessarily reduce pre-competitive anxiety, it may have some influence on better sports performance, which justifies the inclusion of ER training programs as part of the regular training of athletes.

Likewise, Giles et al. (2017) demonstrated that a successful cognitive re-evaluation is related not only to regular physical activity, but also to a greater oxygenation of the brain areas involved in ER. This contrasts with what was pointed out by Zhang et al. (2018), who related PA as an important factor for improving skills for implicit ER, and the recommendations of Strasser and Fuchs (2015), who associate PA as an important contention factor in the face of the potential damage induced by psychological stress, since it increases the modulation of norepinephrine, dopamine and serotonin, aspects which, in turn, have an impact on the improvement of cognitive processes and emotional regulation.

Due to conditions related to urban lifestyle, some people drastically reduce their levels of physical activity, which has an unfavorable effect in regulating emotions (Rofey, McMakin, Shaw, \& Dahl, 2013). However, those people who exhibit higher levels of emotional expression and positive reappraisal manifest, in turn, a greater BMI control, higher rates of daily physical activity and better sleep hygiene (Shimanoe et al., 2015).

\section{$R E$ and Healthy Eating}

In this category twenty articles were located, of which eight were experimental and twelve correlational. All of them present the conceptual and operational definitions of the case, describe the statistical procedures carried out for the analysis of the information, respond to the research question and hypothesis formulated, give an account of the correspondence between the reported results, the limitations found and the conclusions drawn. With only one exception, they present, both a detailed description of the steps followed to obtain the information, and the due indicators of reliability and validity of the tests used to measure the constructs. 


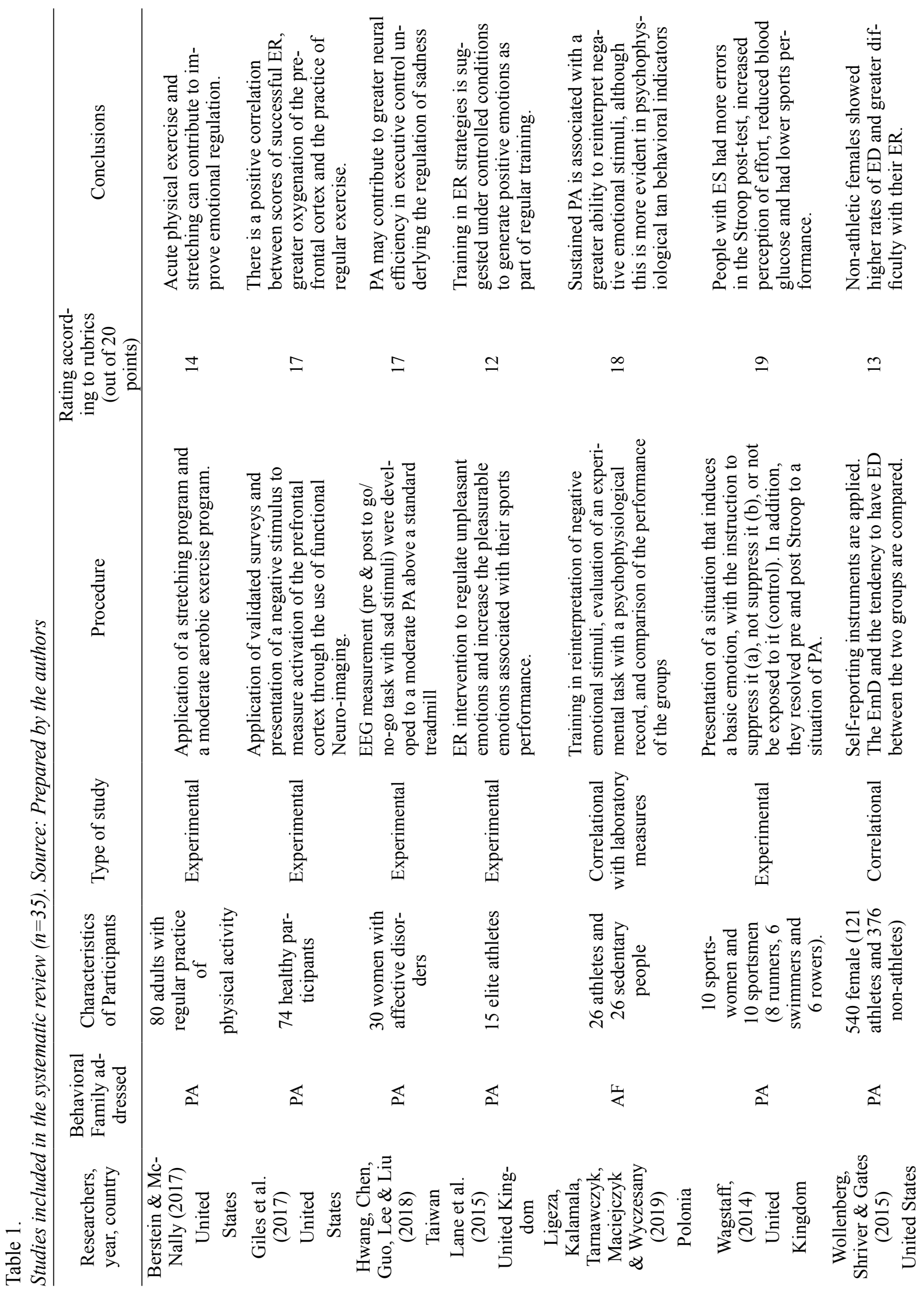




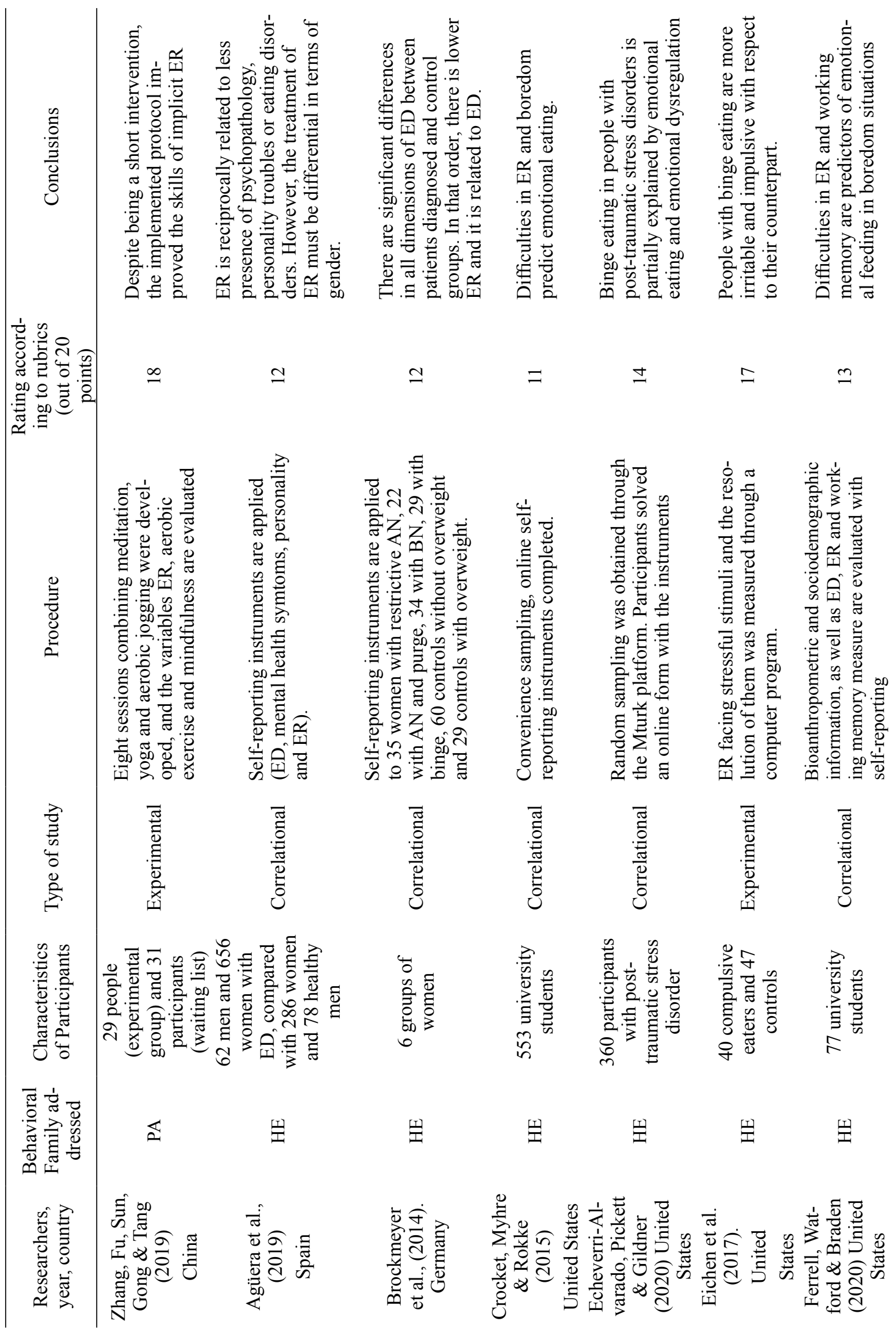


Gómez-Acosta, A., \& Londoño Pérez, C.

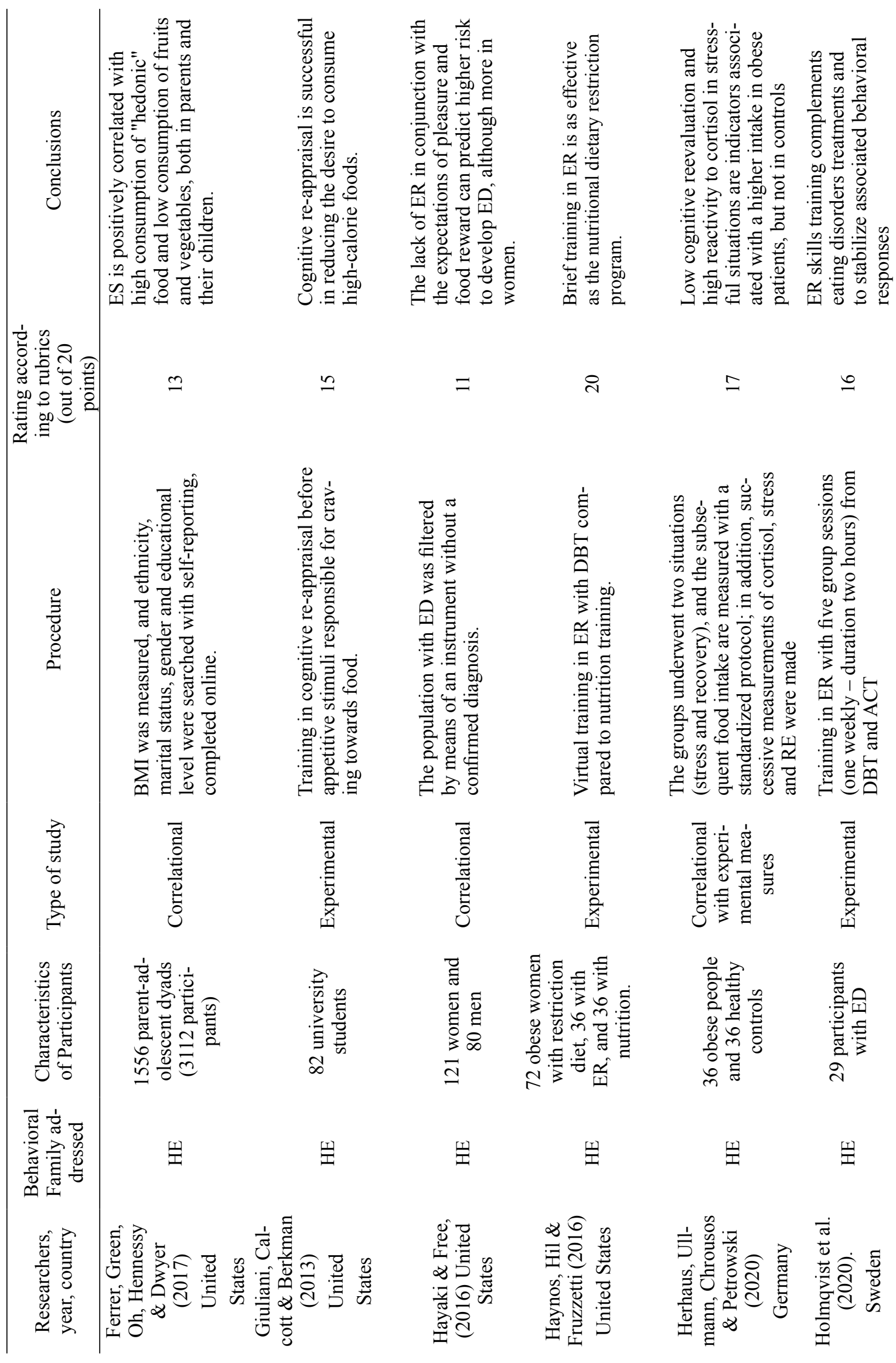


$E R \& B E B$ in adults

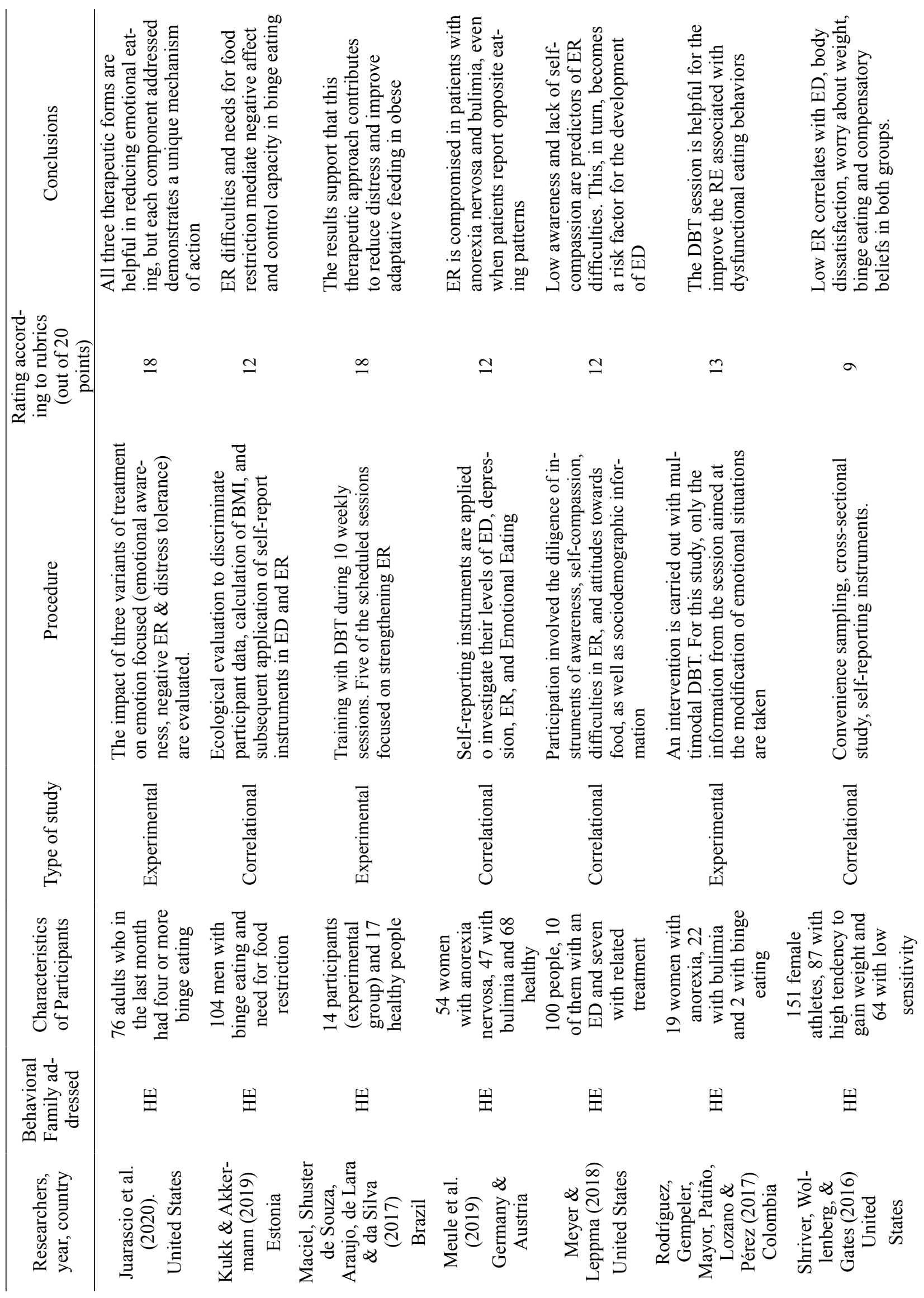




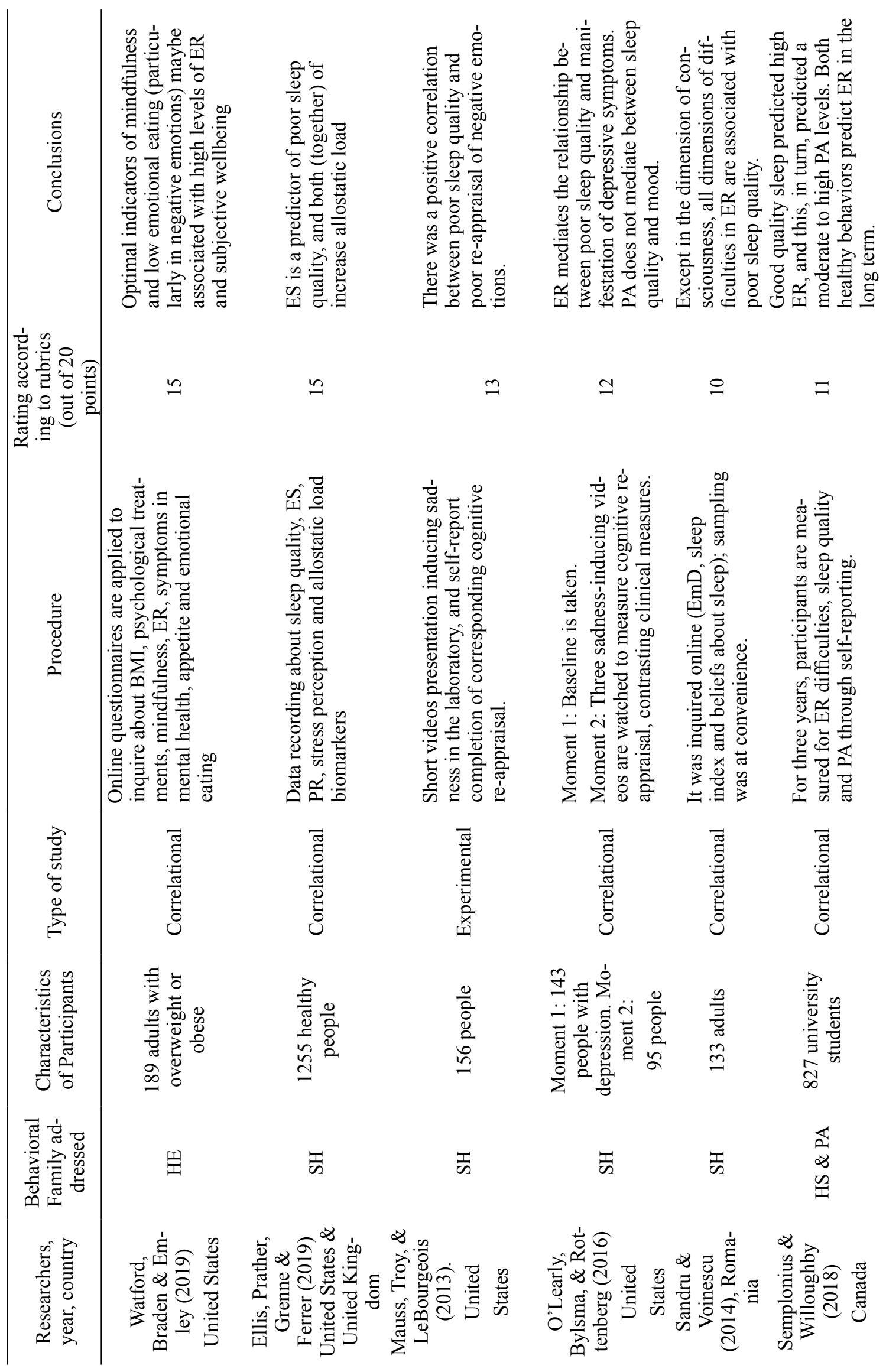




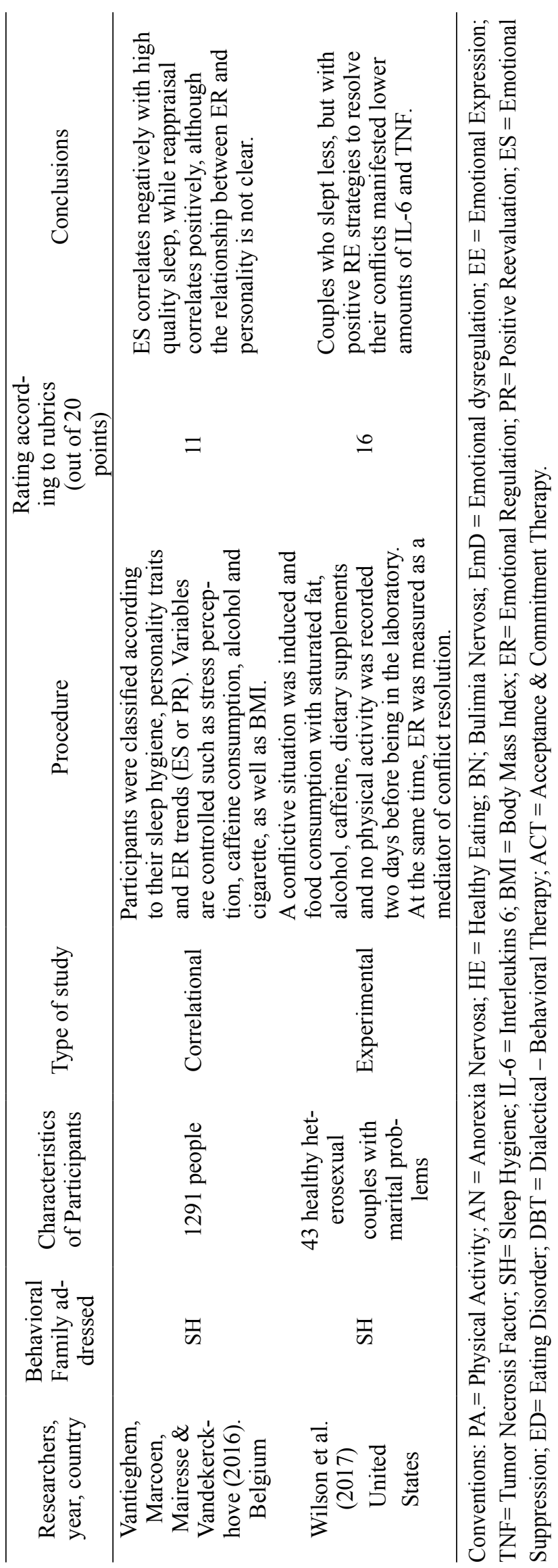


Despite this, only half of the studies report the inclusion /exclusion criteria determined for sampling and 10 of them do not present a high internal validity since they do not offer a high degree of variable control (within which there is one experimental study). Only four study accounts for the way the calculation of the sample was carried out, and none explicitly indicates any effect size coefficient. These studies were conducted in the United States (12), Germany (three), Spain (one), Sweden (one), Estonia (one), Brazil (one), Austria (one), and Colombia (one); so a drastic effect be expected given the cultural differences of both countries in the ER measurement.

Participants were found who decide to avoid or reduce negative emotions by means of compulsive eating, which was evidenced from self-reported measurement (EcheverriAlvarado et al., 2020; Kukk \& Akkermann, 2019), and laboratory controlled records (Eichen et al., 2017; Herhaus et al., 2020). This coping strategy is a mechanism learned and reinforced during the psychological development of individuals that correlates with boredom (Crocket et al., 2015; Ferrell et al., 2020) and with emotional suppression (Harrist, Laura, Topham, Shriver \& Page, 2013).

It was also found that people with restrictive anorexia, purged anorexia, and bulimia nervosa present greater difficulties in their ER in the dimensions of non-acceptance of the situation, few behaviors directed towards adaptative goals, impulsiveness, few management strategies, lack of awareness of their emotions and emotional clarity (Brockmeyer et al., 2014), as well as lower levels of full awareness and self-compassion (Meyer \& Leppma, 2018; Watford et al., 2019), despite the fact that these patients show diverse eating behaviors (Meule et al., 2019). These same problems are correlated with dissatisfaction with body shape and weight, binge-eating tendencies and development of compensatory beliefs, particularly concerning food and physical exercise (Shriver et al, 2016).

On the other hand, Ferrer et al. (2017) highlight that emotional suppression in stressful conditions has a direct effect on both the preference for high-calorie foods (called "hedonic foods") on the part of adults and their adolescent children. However, it is identified that, when comparing by sex, the presence of difficulties in ER correlates with the subjective value given to food as a reinforcer, so that women, when faced with overwhelming situations, would have a greater tendency to choose emotional eating as a way of coping (Hayaki \& Free, 2016); this event is associated with the need to propose differential preventive and therapeutic approaches based on the gender (Agüera et al., 2019).

In response to the above, it is necessary that training in positive reevaluation (Giuliani et al, 2013) and particularly those developed under third-generation models such as dialectical behavioral therapy (DBT), could contribute to the management of the difficulties in ER that precede behaviors such as food restriction and compulsive eating (Holmqvist et al., 2020; Juarascio et al., 2020; Maciel et al., 2017; Rodríguez et al., 2017). People can select a situation to avoid contact with foods that trigger the compulsive response, eat substitute foods, guide their attention towards foods with lower caloric value, re-evaluate the intake depending on their consequences and modulate the consumption response to contribute to the systematic reduction of anxiety. In this way, they can achieve specific objectives such as lowering the BMI or cholesterol levels (Giuliani \& Berkman, 2015). Likewise, people can increase their self-efficacy regarding healthy behaviors associated with both good nutrition and reduction of sedentary lifestyle (Isasi, Ostrovsky \& Wills, 2013).

\section{$R E$ and Sleep Hygiene}

Regarding the relationship between ER and sleep hygiene, seven articles were obtained, corresponding to three experimental investigations and four correlational studies. All of them give an account of the information collection process, describe the statistical procedures implemented for data analysis, report results that answer the research question and hypothesis, and it is possible to identify that they are consistent with the obtained figures, the inferences made and the limitations exposed.

However, one of them does not define conceptually and operationally the variables of interest; four of them do not account for a sufficient degree of control that allows to conclude the presence of a high internal validity (including the two experimental studies); two of them do not present the reliability/validity indicators of the measurement instruments implemented, while two others did not describe the corresponding inclusion / exclusion criteria, and none report neither the procedure used for the calculation of the sample, nor an indicator of the effect size. These studies were conducted in the United States (three), Romania (one), United Kingdom (one), Canada (one) and Belgium (one), so differences in ER understanding and measurement can be more biased by cultural differences, which makes it difficult (in principle, although it is not the rule) the comparison between them.

On the other hand, documented evidence highlights that people who are exposed to stimuli with strong emotional content, but who also refer poor sleep quality, may present more symptoms associated with a negative mood and poor positive reappraisal skills (Mauss et al., 2013), which is further corroborated with the increase in emotional 
dysregulation indicators (O'Learly et al., 2016), that can even affect the PA realization (Semplonius \& Willoughby, 2018). Along this line, Sandru and Voinescu (2014) identified that people who have a poor quality sleep have a harder time accepting situations, manifest few adaptive behavior management strategies, show greater impulsivity/irritability, and report lack of emotional clarity, high levels of catastrophization, a perception of emotional dysregulation, as well as problems of attention, concentration, memory and executive functions which, in turn, can generate less positive emotions and fewer optimistic reasoning (Sandru \& Voinescu, 2014) .

Likewise, Vantieghem et al. (2016) report that those who show the greatest amount of suppression as an emotional regulation strategy have a lower sleep quality, even when this situation is not directly related to any specific personality trait. However, this situation (sleep deprivation), although it may eventually affect the future ER, does not necessarily compromise an adequate conflict resolution, as long as a previous training in positive reappraisal takes place (Wilson et al., 2017).

When contrasting with other references it is evident that sleep problems can be precursors of the lack of emotional regulation due to insufficient capacity to restore the nervous and endocrine systems (Irish et al., 2014), and to influence areas such as the medial prefrontal cortex, the anterior cingulate cortex, the amygdale, and the striate cortex (Palmer \& Alfano, 2017). This can affect emotional reactivity, impulse regulatory control, sensitivity to punishment, perception of rewards, and motivational salience towards the achievement of certain objectives (Fairholme $\&$ Manber, 2015). It may also lead to not very successful ER strategies (Palmer \& Alfano, 2017), with a significant impact on BMI increase (Rofey et al., 2013), and in the growth of the allostatic load (Ellis et al., 2019). However, it has also been reported that not necessarily the emotions experienced in the course of the day predict the quality of sleep the following night (Simor, Krietsch, Koteles \& McCrae, 2015), so more research is suggested with respect to such interactions.

\section{Discussion}

Despite the ER potential as a set of processes related to the BEB behavioral aggregates, there are few studies that explicitly address this psychological process with observations and controlled measurements of the identified interactions. There are even fewer studies that explicitly refer to the effect size, which makes it impossible both to compare whether ER presents homogeneous effects on the families of the behaviors addressed, and demonstrate the possible heterogeneity of the subsets of the revised variables (Sánchez-Meca \& Botella, 2010). Taking into account that 17 of the studies examined do not correspond to research with experimental measurements, it is suggested to develop more studies that enable demonstrate both in controlled environments (with observation, recording and analysis of biomarkers), and in real human contexts (with population- based and longitudinal studies) the effective interdependence that theoretically exist between RE and BEB behaviors.

Likewise, it is desirable that future research ensure characteristics such as: including sufficient conceptual and operational definitions of variables; demonstrate an optimal degree of control that allows internal validity to be assured; present the validity and reliability indicators of the corresponding instruments; describe the defined inclusion, exclusion and sampling criteria; give an account of the steps developed for data collection and analysis; report results that strictly respond to the research questions and hypotheses formulated, and explicitly identify both the limitations and new possibilities of the studies. All this in order to contribute with research of high methodological quality that, in turn, can provide more conclusive evidence regarding the relationship between ER and the behavioral aggregates addressed.

Regarding the contributions, although in this document it has been stated that there is more empirical evidence in favor of the preponderance that cognitive reappraisal would have versus emotional suppression as a strategy to achieve an adequate ER, authors such as Luong, Wrzos, Wagner and Riediger ( 2016) suggest that the inappropriate and unpleasant connotation of emotional suppression should be reexamined in light of the meanings given to emotions in each culture, which, in turn, could have some interference in the practice of any of the three behavioral aggregates. To give an example, according to $\mathrm{Hu}$ et al. (2014), emotional suppression reactions in Eastern cultures are not necessarily linked to the development of somatic illness symptoms (which have the potential to become factors for initiating healthy practices), as it is more likely to happen to those who are part of the western culture. To that extent, authors such as Kashdan, Young y Machell, (2015) postulate that emotional suppression can also be adaptive, to the extent that it allows a better adjustment to personal expectations and competences, and in this way, contribute to a positive state of health, for example, when people set for themselves goals as the reduction of weight through physical exercise.

Similarly, it is found that in several of the studies described, the strategies of emotional regulation are assumed to 
be monolithic, not susceptible of being modified according to the contextual conditions in which the person functions (Dore, Silvers \& Ochsner, 2016), their current emotional goals (Dixon-Gordon, Aldao \& De los Reyes, 2015; Kashdan et al., 2015), differences in personality style (Vantieghem et al., 2016), cultural valuations and differences in prevalence and health incidents in the regions (Hu et al., 2014). Given this situation, it would be convenient to include more holistic conceptual variants such as the proposal of flexibility in emotional regulation (Aldao, Sheppes \& Gross, 2015) as a co-determining factor of BEB behaviors.

It is also relevant that the positive repercussions of sleep quality, moderate physical activity or balanced diet are related to a sustained practice over long periods of time, whereas ER strategies are assessed according to the immediate context (Mauss et al., 2013). This would pose some difficulty to research, since there would be two types of practices (BEB on the one hand and RE on the other) which are not necessarily synchronized in terms of their evolution and manifestation. In this regard, as ER strategies are more fluctuating and dependent on specific circumstances, it becomes a challenge for health and behavioral sciences to account for the interdependence relationships of two equally important dimensions in reducing stress levels manifested by people (Myers et al., 2012) and for attaining a greater well-being, quality of life and general health (Gross, 2015).

Everything mentioned up to this point implies that, in order to understand the complexity that this relationship poses, further studies must account for associations between positive / negative affect and cognitive - social processes that are related to ER, such as optimism - pessimism (Jenaabadi et al., 2015), or compensatory health beliefs (Shriver et al, 2016, within the framework of an integrating model that should specify the conditions established by the physical and sociocultural context under which these ER strategies operate, depending on their possible repercussion in the three behavioral aggregates related to BEB.

Although the objective of this study was not to directly evaluate the work related to the interaction between ER processes and BEB behaviors, the reflection on the findings does allow generating new investigations in which ER is manipulated and the effect size is contrasted for the increase of health self-care behaviors (Gómez-Acosta, 2017). This may enable the provision of evidence regarding the ER relationship, the increase in BEB behaviors and adherence to treatment/ reduction of health situations such as morbid obesity, eating disorders, cardiovascular diseases, diabetes mellitus, insomnia and other chronic non-communicable diseases (Gómez-Acosta, 2018).
On the other hand, the development of new predictive and explanatory models should be promoted, allowing not only a better understanding of the confluence of intervening factors in the ER relationship and the sustained practice of adult BEB behaviors (including cognitive and contextual factors), but that also seek the strengthening of cognitive reappraisal and positive emotions for the reduction of adverse events and improvement of habits that positively impact on health (Cerolini, Ballesio \& Lombardo, 2015; Gross, 2015).

The following is the list of limitations of the present review. In the first place, no studies were found in Spanish that related ER to BEB behaviors that fully met the defined criteria, which reduces the possibilities of generalization of this analysis to the Spanish-speaking population, so it would be essential to encourage the development of research projects in this regard in Latin America. Second, although there are studies that report having investigated ER, it is found that what is actually tackled are constructs such as positive / negative mood, coping, stress, depression, rumination, alexithymia, and emotional lability, among others, which is associated with difficulties in the delimitation of the concept, in coherence with what Palmer and Alfano stipulated (2017). Third, and in addition to the above, different instruments were used to measure ER (Difficulties in Emotion Regulation Questionnaire [DERS], Cognitive Emotion Regulation Questionnaire [CERQ], Emotion Regulation Questionnaire [ERQ]), which allows obtaining ER dimensions and different metrics that make comparisons between studies difficult. Finally, it is reported that the article subscribes a publication bias, by selecting only articles from high impact indexed journals, to the detriment of the inclusion of documents compiled by institutional repositories.

It can be concluded that, in effect, ER has an impact on the physical health of people, and is not only directly linked to the processes of psycho-neuro-endocrine-immune homeostasis and associated epigenetic correlates, but can also indirectly affect this balance through the interaction that RE holds with the behaviors associated with BEB. In this case, it is convenient to develop more research that will allow, on the one hand, have a better understanding of the reciprocal functioning of these systems and their spiraling feedback, and on the other hand, that will lead to a better understanding of the relationships between ER and other psychological factors underlying health protective practices (Ellis et al., 2019; Gómez-Acosta, 2018).

\section{Conflict of interest}

The authors declare they have no conflicts of interests. 


\section{Referencias}

Agüera, Z., Paslakis, G., Munguía, L., Sánchez, I., Granero, R., Sánchez-González, J., et al. (2019). Gender-related patterns of emotion regulation among patients with eating disorders. Journal of Clinical Medicine, 8(161), 1-16. doi : 10.3390/ jcm8020161.

Aldao, A., Sheppes, G., \& Gross, J. (2015). Emotion Regulation Flexibility. Cognitive Therapy Research, 39, 263-278. doi: 10.1007/s10608-014-9662.

Appleton, A.A., \& Kubzansky, L. D. (2014). Emotion regulation and cardiovascular disease risk. In J. J. Gross (Ed.), Handbook of Emotion Regulation (2nd ed., pp. 596-612). New York, NY: Guilford.

Baker, P., Dobbins, M., Soares, J., Francis, D., Weightman, A., \& Costello, J. (2015). Public Health interventions for Increasing Physical Activity in Children, Adolescents and Adults: An Overview Review (Protocol). Cochrane Database of Systematic Review, 1, CD011454. doi: 10.1002/14651858.CD11454

Berstein, E., \& McNally. R. (2017). Acute aerobic exercise helps overcome emotion regulation deficits. Cognition and Emotion, 31(4), 834-843, doi: 10.1080/02699931.2016.1168284.

Bonanno, G. A., \& Burton, C. L. (2014). Regulatory flexibility: An individual differences perspective on coping and emotion regulation. Perspectives on Psychological Science, 8, 591-612, doi: 10.1177/1745691613504116.

Brockmeyer, T., Skunde, M., Wu, M., Bresslein, E., Rudofsky, G., Herzog, W., \& Friederich, H. (2014). Difficulties in emotion regulation across the spectrum of eating disorders. Comprehensive Psychiatry 55, 564 - 571, doi: 10.1016/j. comppsych.2013.12.001.

Cerolini, S., Ballesio, A., \& Lombardo, C. (2015). Insomnia and emotion regulation: recent findings and suggestions for treatment. Journal of Sleep Disorders and Management, 1 (1), 1-5, doi: 10.23937/2572-4053.1510001

Crocket, A., Myhre, S., \& Rokke, P. (2015). Boredom proneness and emotion regulation predict emotional eating. Journal of Health Psychology, 20(5), 670-680, doi 10.1177/1359105315573439.

DeSteno, D., Gross, J., \& Kubzansky, L. (2013). Affective science and health: The importance of emotion and emotion regulation. Health Psychology, 32, 474-486. doi: 10.1037/ a0030259.

Dixon-Gordon, K., Aldao, A., \& De los Reyes, A. (2015). Emotion regulation in context: examining the spontaneous use of strategies across emotional intensity and the type of emotion. Personality and Individual Differences, 86, 271276, doi: 10.1016/j.paid.2015.06.011.

Dore, B., Silvers, J., \& Ochsner, K. (2016). Toward a personalized science of emotion regulation. Social and Personality Psychology Compass, 10(4), 171-187, doi: 10.1111/ spc3.12240.
Echeverri-Alvarado, B., Pickett, S., \& Gildner, D. (2020). A mdel of post-traumatic stress symtoms of binge eating eating through emotion regulation difficulties and emotional eating. Appetite, 150, 104659. doi: 10.1016/j. appet.2020.104659

Eichen, D., Chen, E., Boutelle, K., \& McCloskey, M. (2017). Behavioral evidence of emotion dysregulation in binge eaters. Appetite, 111, 1-6, doi: 10.1016/j.appet.2016.12.021.

Ellis, E., Prather, A., Grenen, E., \& Ferrer, R. (2019). Direct and indirect associations of cognitive reappraisal and suppression with disease biomarkers. Psychology \& Health, 34(3), 336-354. doi: 10.1080/08870446.2018.1529313

Etchemendy, E., Herrero, R., Espinoza, M., Molinary, G., Corno, G., Carrillo-Vega, A., ...Baños, R. (2016). "Good things never last": dampening positive emotions influences our optimism levels. Anales de Psicología, 32(3), 704-709. doi: 10.6018/analesps.32.3.261631.

Fairholme, C., \& Manber, R. (2015). Sleep, emotions and emotion regulation: An Overview. En K. Babson \& M. Feldner (Eds). Sleep and Affect: Assessment, Theory and Clinical Implications (pp. 45-61). New York: Academic Press, doi: 10.1016/B978-0-12-417188-6.00003-7.

Ferrell, E., Watford, T., \& Braden, A. (2020). Emotion regulation difficulties and impaired working memory interact to predict boredom emotional eating. Appetite, 144, 104450. doi: 10.1016/j.appet.2019.104450.

Ferrer, R., Green, P., Oh, A., Hennessy, E., \& Dwyer, L. (2017). Emotion suppression, emotional eating, and eating behavior among Parent - Adolescent dyads. Emotion, 17(7), 10521065, doi: 10.1037/emo0000295.

Giles, G., Cantelon, J., Eddy, M., Brunye, T., Urry, H., Mahoney, C., \& Kanarek., R. (2017). Habitual exercise is associated with cognitive control and cognitive reappraisal success. Experimental Brain Research, 235(12), 3785-3797, doi: 10.1007/s00221-017-5098-x.

Giuliani, N., \& Berkman, E. (2015). Craving is an affective state and its regulation can be understood in terms of the extend process model of emotion regulation. Psychological Inquiry, 26(1), 48-53, doi: 10.1080/1047840X.2015.955072.

Giuliani, N., Calcott, R., \& Berkman, E. (2013). Piece of cake. Cognitive reappraisal of food craving. Appetite, 64, 56-61, doi: 10.1016/j.appet.2012.12.020.

Gómez-Acosta, A. (2017). Predictores psicológicos del autocuidado en salud. Hacia la Promoción de la Salud, 22(1), 101-112. doi: 10.17151/hpsal.2017.22.1.8

Gómez-Acosta, A. (2018). Factores psicológicos predictores de estilos de vida saludables. Revista de Salud Pública, 20(2), 155-162. doi: 10.15446/rsap.v20n2.50676

Gómez-Ortega, O., \& Amaya-Rey, M. (2013). ICrESAI IMeCI: instrumentos para elegir y evaluar artículos científicos para la investigación y la práctica basada en la evidencia. Aquichan, 13(3), 407-420, doi: 10.5294/aqui.2013.13.3.8. 
Gómez-Ortega, O., \& Amaya-Rey, M. (2016). Meta-análisis, efecto del trasplante renal, hepático, cardiaco y pancreático - renal en la calidad de vida de las personas adultas (tesis doctoral no publicada). Bogotá: Universidad Nacional de Colombia.

González, M., Ramírez, G., Del Mar, M., \& Londoño, C. (2017). Estrategias de control, evitación y regulación emocional: el papel diferencial en pensamientos repetitivos negativos e intrusivos. Ansiedad \& Estrés, 23, 84 - 90. doi: 10.1016/j. anyes.2017.09.005

Gross, J. (2014). Emotion regulation: conceptual and empirical foundations. En J. Gross (Ed). Handbook of Emotion Regulation (Second Edition). New York: The Guilford Press.

Gross, J. (2015). Emotion Regulation: Current Status and Future Prospects. Psychological Inquiry, 26(1), 1-26, doi: 10.1080/1047840X.2014.940781.

Harrist, A.W., Laura, H. T., Topham, G. L., Shriver, L. H., \& Page, M. C. (2013). Emotion regulation is related to children's emotional and external eating. Journal of Developmental and Behavioral Pediatrics, 34(8), doi: 10.1097/DBP.0b013e3182a5095f.

Hayaki, J., \& Free, S. (2016). Positive and negative eating expectancies in disordered eating among women and men. Eating Behaviors, 22, 22-26, doi: 10.1016/j. eatbeh.2016.03.025.

Haynos, A., Hill B., \& Fruzzetti, A. (2016). Emotion regulation training to reduce problematic dietary restriction: an experimental analysis. Appetite, 103, 265-274, doi: 10.1016/j. appet.2016.04.018.

Herhaus, B., Ullmann, E., Chrousos , G., \& Petrowski, K. (2020). High/low cortisol reactivity and food intake in people with obesity and healthy weight. Translational Psychiatry, 10(40), 1-8. doi: 10.1038/s41398-020-0729-6.

Holmqvist, K., Lowén, A., Hellerstedt, L., Bergcrona, L., Salerud, M., \& Zetterqvist, M. (2020). Emotion regulation group skills training: a pilot study of an add-on treatment for eating disorders in a clinical setting. Journal of Eating Disorders, 8(12), 2-11. doi: 10.1186/s40337-020-00289-1.

Hoorelbeke, K., Koster, E., Demeyer, I., Loeys, T., \& Vanderhasselt, M. (2016). Effects of cognitive control training on the dynamics of (mal) adaptive emotion regulation in daily life. Emotion 16(7), 945-956, doi: 10.1037/ emo0000169.

Hu, T., Zhang, D., Wang, J., Mistry, R., Ran, G., \& Wang, X. (2014). Relation between emotion regulation and mental health: a meta-analysis review. Psychological Reports: Measures \& Statistics, 114 (2), 341-362, doi: 10.2466/03.20. PR0.114k22w4.

Hwang, R. J.., Chen, H. J., Guo, Z. X., Lee, Y. S., \& Liu, T. Y. (2018). Effects of aerobic exercise on a sad emotion regulation in young women: an electroencephalograph study. Cognitive Neurodynamics, 13(1), 33-43. doi: 10.1007/ s11571-018-9511-3.
Irish, L., Kline, C., Gunn,H., Buysse, D., \& Hall, M. (2014). The role of sleep hygiene in promoting public health: a review of empirical evidence. Sleep Medicine Reviews, 1 ,114, doi: 10.1016/j.smrv.2014.10.001.

Isasi, C., Ostrovsky, N., \& Wills, T. (2013). The association of emotion regulation with lifestyle behavior in inner-city adolescents. Eating Behaviors, 14, 518-521, doi: 10.1016/j. eatbeh.2013.07.009.

Jenaabadi, H., Ali-Ahani, M., \& Sabaghi, F. (2015). Examining the relationship of optimism and emotion regulation strategies with general health among students of University of Sistan and Baluchestan. Health, 7, 865-872. doi: 10.4236/ health.2015.77102.

Juarascio, A., Parker, M., Manasse, S., Barney, J., Wyckoff, E., \& Dochat, C. (2020). An exploratory component analysis of emotion regulation strategies for improving emotion regulation and emotional eating. Appetite, 104634, doi: 10.1016/j. appet.2020.104634 .

Kashdan, T., Young, K., \& Machell, K. (2015). Positive emotion regulation: addressing two myths. Current Opinion in Psychology, 3, 117-121, doi: 10.1016/j.copsyc.2014.12.012.

Kukk, K., \& Akkermann, K. (2019). Emotion regulation difficulties and dietary restraint independently predict binge eating among men. Eating and Weight Disorders Studies on Anorexia, Bulimia and Obesity. doi: 10.1007/ s40519-019-00791-9.

Lane, A., Davenport, T., Friesen, A., Beedie, C., Fullerton, C., \& Stanley, D. (2015). How should I regulate my emotions if I want to run faster? European Journal of Sport Science, 16(4), 465-472, doi: 10.1080/17461391.2015.1080305.

Lee, J., Kosterman, R., Jones, T., Herrenkohl, T., Rhew, I., Catalano, R., \& Hawkins, J. (2016). Mechanisms linking high school graduation to health disparities in young adulthood: a longitudinal analysis of the role of health behaviours, psychosocial stressors, and health insurance: Public Health, 1, 1-9. doi: 10.1016/j.puhe.2016.06.010.

Ligeza, T., Kalamala, P., Tarnawczyk, O., Maciejczyk, M., \& Wyczesany, M. (2019). Frequent physical exercise is associated with better ability to regulate negative emotions in adult women: The electrophysiological evidence. Mental Health and Phisical Activity, 17, 100294. doi: 10.1016/j. mhpa.2019.100294

Lim, S., Allen, K., Bhutta, Z., Dandona, L., Forouzanfar, M., ... Murray, C. (2016). Measuring the health-related Sustainable Development Goals in 188 countries: a baseline analysis from the Global Burden of Disease Study 2015. The Lancet, 388, 1813-1850. Doi: 10.1016/ S0140-6736(16)31467-2.

López-Espinoza, A., Martínez, A. G., Aguilera, V., LópezUriarte, J. P., Housni, F., Ruelas, M. G. \& Vásquez., L. (2014). El hábito de comer. En A. López-Espinoza y C. R. Magaña (Eds.). Hábitos alimentarios: Psicobiología y socioantropologia de la alimentación (pp. 129-137). México: Mc Graw-Hill Education. 
Luong, G., Wrzos, C., Wagner G., \& Riediger, M. (2016). Bad moods may not be so bad: valuing negative affect is associated with weakened affect-health links. Emotion, 16(3), 387-401. doi: 10.1037/emo0000132.

Maciel, A., Shuster de Souza, L., Araujo, R., de Lara, W., \& da Silva, M. (2017). Effects of a dialectical behavior therapy-based skills group intevention for obese individuals: a Brazilian pilot study. Eating and Weight Disorders - Studies on Anorexia, Bulimia and Obesity, 24(6), 1099-1111. doi:10.1007/s40519-017-0461-2.

Manchado, R., Tamames, S., López, M., Mohedano, L., D’Agostino, M., \& Veiga de Cabo, J. (2009). Revisiones Sistemáticas Exploratorias. Medicina y Seguridad del Trabajo, 55(216), 12-19. Recovered from http://scielo. isciii.es/pdf/mesetra/v55n216/especial.pdf

Mauss, I., Troy, A., \& LeBourgeois M. (2013). Poorer sleep quality is associated with lower emotion-regulation ability in a laboratory paradigm, Cognition and Emotion, 27(3), 567-576, doi: 10.1080/02699931.2012.727783.

Meule, A:, Richard, A., Schnepper, R., Reichenberger, J., Georgii, C., et al., (2019). Emotion regulation and emotional eating in anorexia nervosa and bulimia nervosa. Eating Disorders, 1 - 17. doi: 10.1080/10640266.2019.1642036

Meyer, L., \& Leppma, M. (2018). The Role of Mindfulness, Self-Compassion, and Emotion Regulation in Eating Disorder Symptoms Among College Students. Journal of College Counseling, 22(3), 211 - 224. doi: 10.1002/ jocc. 12138.

Myers, S., Sweeney, A., Popick, V., Wesley, K., Bordfeld, A., \& Fingerhut, R. (2012). Self - care practices and perceived stress levels among psychology graduate students. Training and Education in Professional Psychology, 6 (1), 55-66, doi: $10.1037 / \mathrm{a} 0026534$.

O’Learly, K., Bylsma, L., \& Rottenberg, J. (2017). Why might poor sleep quality lead to depression? A role for emotion regulation. Cognition and Emotion, 31(8), 1698-1706, doi: 10.1080/02699931.2016.1247035.

Palmer, C., \& Alfano, C. (2017). Sleep and emotion regulation: an organizing, integrative review. Sleep Medicine Review, 31, 6-16, doi: 10.1016/j.smrv.2015.12.006.

Rodríguez, M., Gempeler, J., Mayor, N., Patiño, C., Lozano, L., \& Pérez, V. (2017). Emotion dysregulaion and eating symptoms: analysis of group sessions in patients with eating disorder. Revista Mexicana de Trastornos Alimentarios, 8, 72-81. doi: 10.22201/fesi.20071523e.2017.1.434

Rofey, D., McMakin, D., Shaw, D., \& Dahl R. (2013). Selfregulation of sleep, emotion, and weight during adolescence: implications for translational research and practice. CTS Journal, 6 (3), 238-243, doi: 10.1111/cts.12034.

Romieu, I., Dosus, L., Barquera, S., Blottière, H., Franks, P., ... Willett, W. (2017). Energy balance and obesity: what are the main drivers? Cancer Causes Control 28(3), 247-258, doi: 10.1007/s10552-017-0869-z
Sánchez-Meca, J., \& Botella, J. (2010). Revisiones sistemáticas y meta-análisis: herramientas para la práctica profesional. Papeles del Psicólogo 31(1), 7-17. Recovered from http:// www.papelesdelpsicologo.es/pdf/1792.pdf

Sandru, C., \& Voinescu, B. (2014). The relationship between emotion regulation, dysfunctional beliefs about sleep and sleep quality: an exploratory study. Journal of EvidenceBased Psychoterapies, 14(2), 249-357. Recovered from https://www.questia.com/library/journal/1P3-3481780131/ the-relationship-between-emotion-regulation-dysfunctional

Seligowski, A., \& Orcutt, H. (2015). Examining the Structure of Emotion Regulation: A Factor-Analytic Approach. Journal of Clinical Psychology, 71(10), 1004-1022, doi: 10.1002/ jclp.22197.

Semplonius, T., \& Willoughby, T. (2018). Long -term links between physical activity and sleep quality. Medicine \& Science in Sports \& Exercise, 50(12), 2418-2424. doi: 10.1249/MSS.0000000000001706

Sheppes, G., Suri, G., \& Groos, J. (2015). Emotion Regulation and Psychopathology.Annual Review of Clinical Psychology, 11,379-405, doi: 10.1146/annurev-clinpsy-032814-112739.

Shimanoe, C., Hara, M., Nishida, Y., Nanri, H., Otsuka, Y., Nakamura, K., ... Tanaka., K. (2015). Perceived stress and coping strategies in relation to body mass index: cross-sectional study of 12045 Japanese men and women. PLOS ONE 10(2): e0118105. doi:10.1371/journal.pone.0118105.

Shriver, L., Wollenberg, G., \& Gates, G. (2016). Prevalence of disordered eating and its association with emotion regulation in female college athletes. International Journal of Sport Nutrition and Exercise Metabolism, 26, 240-248, doi: 10.1123/ijsnem.2015-0166.

Simor, P., Krietsch, K., Koteles, F., \& McCrae, C. (2015) Dayto-day variation in subjective sleep quality and emotional states among healthy university students- A 1-week prospective study. International Journal of Behavioral Medicine, 22(5), 625-634. doi: 10.1007/s12529-015-9464-4.

Strasser, B., \& Fuchs, D., (2015). Role of physical activity and diet on mood, behavior, and cognition. Neurology, Psychiatry and Brain Research, 21, 118-126, doi: 10.1016/j. npbr.2015.07.002.

Uskul, K., \&, Horn, A.B. (2015). Emotions and health. In: J., Wright (Ed.) International encyclopedia of social and behavioral sciences (pp.496-501) Elsevier. doi: 10.1016/ B978-0-08-097086-8.25006-X

Vantieghem, I., Marcoen, N., Mairesse, O., \& Vandekerckhove, M. (2016). Emotion regulation mediates the relationship between personality and sleep quality. Psychology and Health, 31 (9), 1064-1079. doi: 10.1080/08870446.2016.1171866.

Wagner, D., \& Heatherton, T. (2014). Emotion and SelfRegulation Failure. In J. Gross (Comp.) Hanbook of Emotion Regulation (Second Edition, pp. 613-624). New York: Guilford Publications Inc. 
Wagstaff, C. (2014). Emotion regulation and sport performance. Journal of Sport \& Exercise Psychology, 36, 401-412, doi: 10.1123/jsep.2013-0257.

Waters, E., McQueen, A., \& Cameron, L. (2014). Perceived Risk and its Relationship to health -Related Decisions and Behavior. In L. Martin \& R. DiMatteo (Eds.) The Oxford Handbook of Health Communication, Behavior Chance and Treatment Adherence (pp. 193-213) New York: Oxford University Press.

Watford, T., Braden, A., \& Emley, E. (2019). Mediation of the association between mindfulness and emotional eating among overweigh individual. Mindfulness, 10, 11153-1162. doi: 10.1007/s12671-018-1064-3

Wilson, S., Jaremka, L., Fagundes, C., Andridge, R., Peng, J, Malarkey., W., ... Kiecolt-Glaser, J. (2017). Shortened sleep fuels inflammatory responses to marital conflict: emotion regulation matters. Psychoneuroendocrinology, 79, 74-83, doi: 10.1016/j.psyneuen.2017.02.015.
Wollenberg, G., Shriver, L., \& Gates, G. (2015). Comparison of disorders eating symtoms and emotion regulation difficulties between female college athletes and non-athletes. Eating Behaviors, 18, 1 -6, doi: 10.1016/j.eatbeh.2015.03.008.

World Health Organization WHO (2010). Recomendaciones Mundiales sobre Actividad Física para la Salud. Ginebra: WHO. Recovered from http://apps.who.int/iris/bitstre am/10665/44441/1/9789243599977_spa.pdf.

Zhang, Y., Fu, R., Sun, L., Gong, Y., \& Tang, D. (2019). How Does Exercise Improve Implicit Emotion Regulation Ability: Preliminary Evidence of Mind-Body Exercise Intervention Combined With Aerobic Jogging and Mindfulness-Based Yoga. Frontiers in Psychology. 10(188), 1-9. doi: 10.3389/ fpsyg.2019.01888. 